\title{
WAVE BOUNDARY CONDITIONS AND OVERTOPPING IN COMPLEX AREAS
}

\author{
Jentsje W. van der Meer ${ }^{1}$, Jan W. Langenberg ${ }^{2}$, Mark Klein Breteler ${ }^{3}$, \\ David P. Hurdle ${ }^{4}$ and Frank den Heijer ${ }^{5}$
}

\begin{abstract}
Low-crested breakwaters or dams may provide some sheltering of flood defence structures like dikes or seawalls. The area around such dams and flood defences very often has a complex geometry. This paper describes the process of transformation of extreme wave boundary conditions in front of such structures to the flood defence structures. Methods to calculate the required crest height for various types of complicated sea walls are given, based on allowable overtopping.
\end{abstract}

\section{INTRODUCTION}

Extreme wave heights and storm surges are often generated by high wind speeds in large areas such as seas and big lakes. Wave boundary conditions for design or assessment of flood defences along the coast can then be calculated using spectral models such as SWAN (Booij et al., 1999). The main wave boundary conditions are storm surge, wave height, period and spectral shape. Sometimes flood defences are partially protected by lowcrested dams, breakwaters or groyns with openings between the structures.

These areas are often limited in size (a few square km's), but very complex as far as wave boundary conditions are concerned. Several studies into the design wave conditions in such areas have been recently carried out in the Netherlands. These studies all applied similar methods to predict the wave conditions at the flood defence structure. In this paper, the harbour of Harlingen is considered in more detail, see Figure 1. Under daily conditions the protecting structures are many meters above the still water level, but during extreme

1 Infram, PO Box 16, 8316 ZG Marknesse, Netherlands. jentsje.vandermeer@infram.nl

2 Wetterskip Fryslân, PO Box 36, 8901 AA Leeuwarden, Netherlands.

j.w.langenberg@wetterskipfryslan.nl

3 WL|Delft Hydraulics, PO Box 177, 2600 MH, Netherlands. mark.kleinbreteler@wldelft.nl 4 Alkyon, PO Box 248, 8300 AE Emmeloord, Netherlands. hurdle@alkyon.nl

5 RIKZ, PO Box 20907, 2500 EX 's Gravenhage, Netherlands; formerly WL|Delft Hydraulics. f.dheijer@rikz.rws.minvenw.nl 
conditions they may become submerged. Specially in the Netherlands the extreme conditions differ considerably from normal daily conditions as return periods up to 10,000 years are considered.

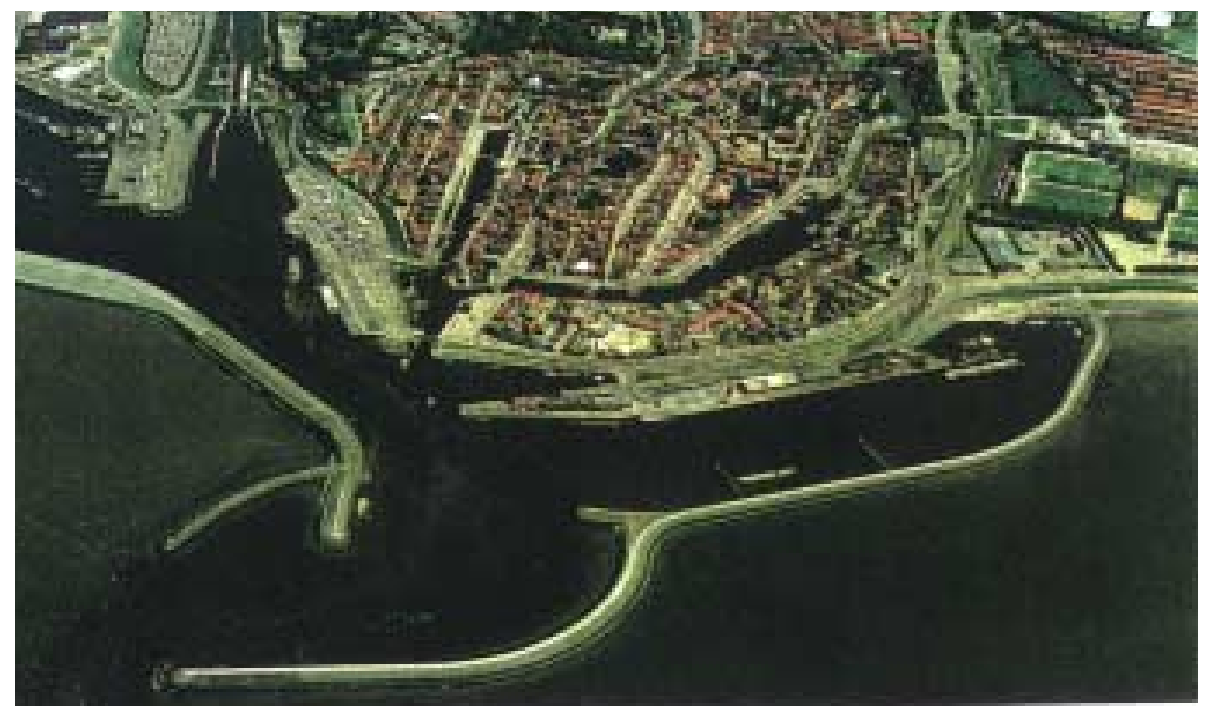

Fig. 1. Example of a complex area: the city of Harlingen. Breakwaters and quays, submerged during design conditions, protect partly the flood defence structures of the city.

\section{PHYSICAL PROCESSES}

The following aspects are characteristic in complex areas for extreme storm surges and will be treated in the paper:

o Wave transmission over low-crested structures

o Wave penetration, diffraction through openings, refraction and reflection

o Local wave growth by extreme wind speeds

o Bi-modal spectra at the structure

o Wave overtopping at various types of structures.

\section{WAVE TRANSMISSION OVER LOW-CRESTED STRUCTURES}

Low-crested structures are obstacles for waves and will dissipate energy. The result is a lower wave height behind the structure. The effect of wave transmission is often described by a wave transmission coefficient only, although there are more effects including a change in spectral shape. Much research has been focused on the wave transmission coefficient, see for example Van der Meer and Daemen, 1992; d'Angremond, Van der Meer and de Jong, 1996; Seabrook and Hall, 1998 and Melito and Melby, 2002. Only the second reference describes smooth and impermeable structures as shown in Figure 1.

Two separate wave transmission investigations have recently been performed, both on smooth impermeable structures. The seaward slope was 1:3.5 or 1:4 and the landward slope $1: 2$ or $1: 4$. In reality the structures are covered by asphalt or by a placed block revetment. Four different crest widths were tested, ranging from $1 \mathrm{H}_{\mathrm{m} 0}$ up to $8 \mathrm{H}_{\mathrm{m} 0}$. The results are shown in Figure 2. It has been shown by many researchers, including the references mentioned above, that for rubble mound structures the crest width has a large influence on wave transmission. This, however, is not the case for smooth structures as given in Fig. 2. 


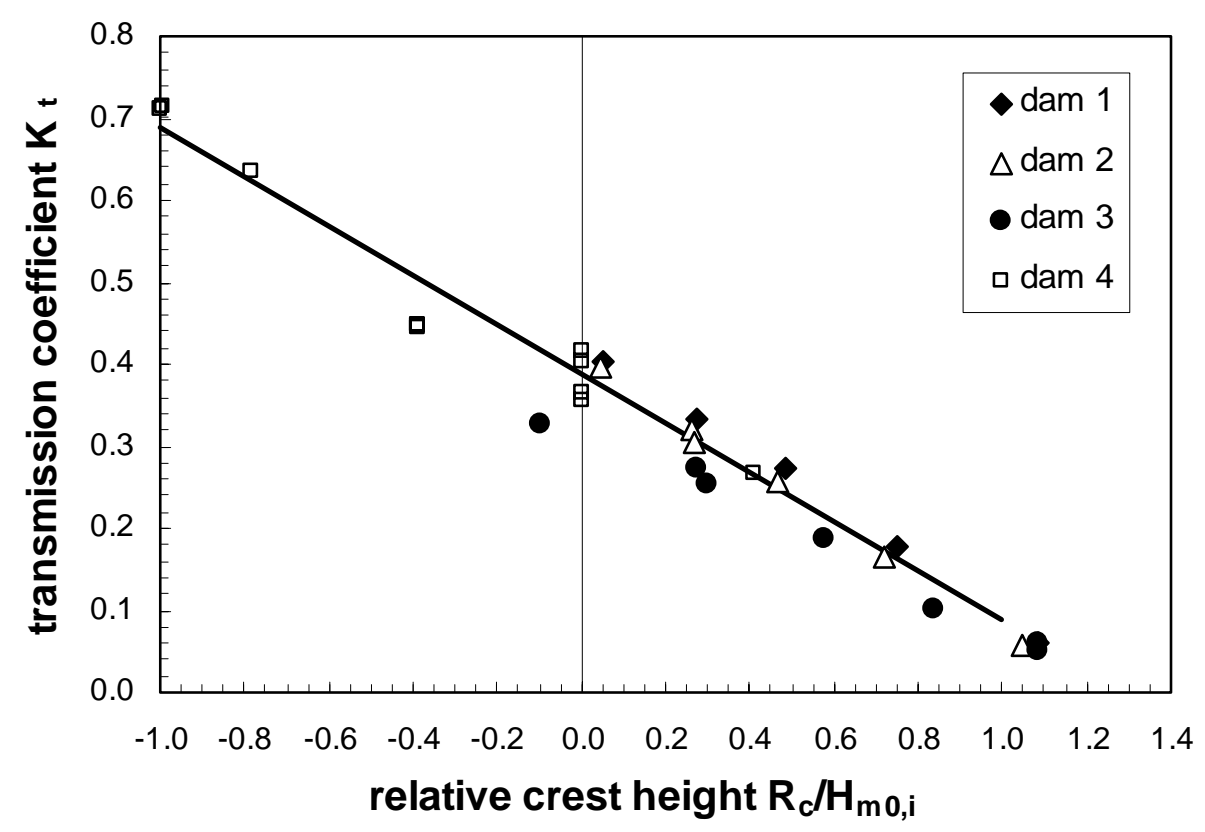

Fig. 2. Wave transmission results for low-crested smooth structures with gentle outer slope and various crest widths

The small influence of crest width on wave transmission on smooth structures can be explained by the way of breaking and the smooth structure itself. Due to the gentle slope waves break and the up-rushing wave tongue jumps over the smooth crest without further wave dissipation.

A very simple relationship can be found to describe the wave transmission for this kind of smooth low-crested structures. From den Heijer, 1998:

$$
K_{t}=0.39-0.3 R_{d} / H_{m 0}
$$

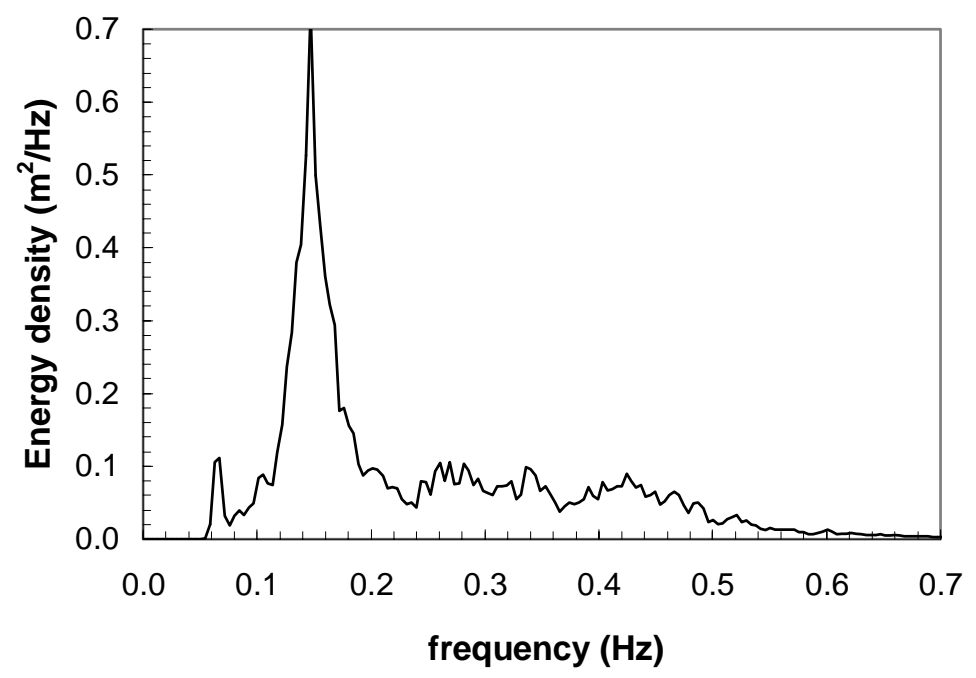

Fig. 3. Energy density spectrum after wave transmission with energy at higher frequencies 
Model tests have shown (Van der Meer et al., 2000) that wave transmission not only involves a reduction in the wave height (using a transmission coefficient), but also changes the spectral shape. Overtopping waves generate more waves behind the low-crested structure, shifting energy to higher frequencies.

Figure 3 gives a good example of a transmitted energy density spectrum. The original peak period is clearly present, but also energy between roughly $1,5 \mathrm{f}_{\mathrm{p}}$ and $3.5 \mathrm{f}_{\mathrm{p}}$, where $\mathrm{f}_{\mathrm{p}}$ is the peak frequency. About $40 \%$ of the total energy is shifted to this frequency range. The method described in Van der Meer et al., 2000, can be used to calculate the transmitted spectrum and can be summarized as follows:

o Calculate the transmission coefficient (for example with formula 1)

o Use the transmission coefficient to reduce the incident spectrum, keeping the spectral shape the same (the reduced incident spectrum in Figure 4)

o The total transmitted energy is then divided and $40 \%$ is brought to the higher frequencies, see Figure 4

o The range of "higher frequencies" is defined by $1.5 f_{p}-3.5 f_{p}$ and the energy is constant in this range.

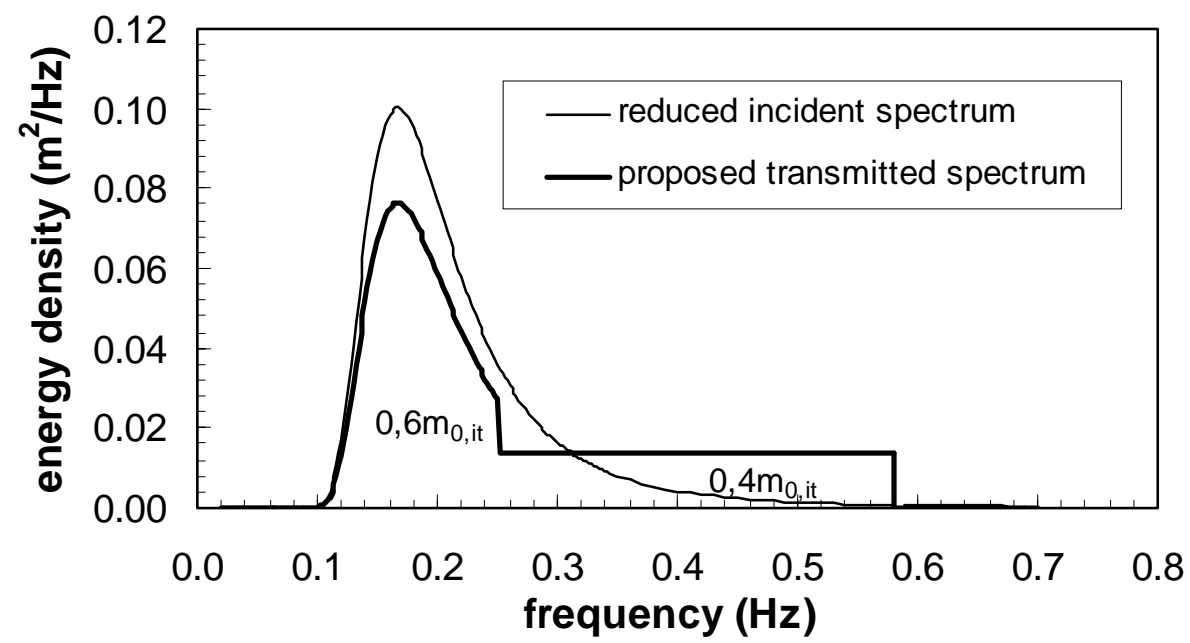

Fig. 4. Calculated reduced spectrum and shift of energy resulting in the final transmitted spectrum

It is clear that the method described above is only a rough estimate and not a scientific approach. More research and analysis is required to come to a more rigorous / well behaved description without discontinuities.

\section{WAVE PENETRATION, DIFFRACTION THROUGH OPENINGS, REFRACTION AND REFLECTION}

Various numerical models are able to calculate effects as wave penetration, refraction and reflection. Some of them are also able to take diffraction into account.

As a part of the transmitted waves have the same peak period as the incident waves outside the complex areas, the numerical models should also take into account the wave development of these transmitted waves, say the left part of Figure 4. The models first calculate the wave height in front of the low-crested structure, then calculate the transmitted 
wave height behind the structure by means of a wave transmission coefficient, reduce the energy to $60 \%$ and calculate the wave transformation up to the flood defences. This gives a wave height in front of the flood defence structure, $\mathrm{H}_{\mathrm{m} 0,1}$, with a wave period, $\mathrm{T}_{\mathrm{p}, 1}$, according to the peak period of the incident waves.

In the recent studies in the Netherlands the phase-averaged SWAN-model (Booij et al., 1999) and the phase resolving model PHAROS (WL|Delft Hydraulics) have been used to compute the wave evolution in the harbour. Figure 5 gives the significant wave height predicted by PHAROS for the complex area in Figure 1, for the situation with wave transmission over the harbour dams. The wave direction is from the Northwest. The Waddensea is on the left of the figure and there are some shallow water areas in front of the breakwaters. The waves from North West penetrate through the harbour entrance, but do not really reach the sea defences (right side of figure). For other wave directions an even smaller proportion of the energy can penetrate the harbour. This means that the wave conditions at the sea defences will be mainly determined by wave transmission and local wave generation.

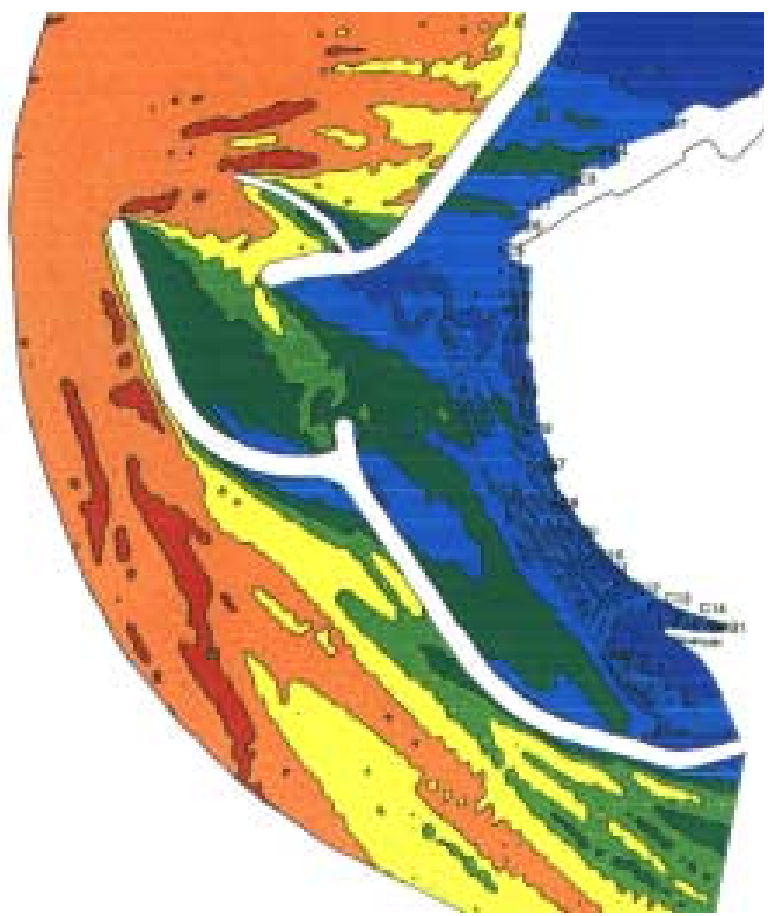

Fig. 5. Wave penetration, diffraction and transmission calculated by PHAROS

\section{SHORT WAVE ENERGY IN COMPLEX AREAS}

\section{Local Wave Growth by Extreme Wind Speeds}

Extreme wind speeds, say from $30-40 \mathrm{~m} / \mathrm{s}$, may generate substantial waves over very short fetches of 200-1000 m. These waves with short periods have to be taken into account if transmitted wave heights are relatively low (less than $1.5 \mathrm{~m}$ ). Most wave growth formulae were developed for longer fetches and very often for lower wind speeds than mentioned above. Wave growth in the North Sea, for example, occurs over tens of kilometers, not tens of meters. A specific study was set-up to find the best formulation for the actual situation. This study has been described in Ris et al., 2002, where Delft Hydraulics, Alkyon and Delft University of Technology worked together. The results will be summarized here. 
From literature, 15 formulations for deep water wave growth were examined and compared. Table 1 gives an overall view, although due to space limitations the full references have not been given. Only a few of them were developed for situations described here. Most of them were not applicable, giving unrealistic predictions for very short fetches. For example, for a wind speed of $40 \mathrm{~m} / \mathrm{s}$ and $200 \mathrm{~m}$ fetch, wave height predictions ranged from 0.3-0.8 m, see Figure 6!

Table 1. Empirical formulations for deep water fetch-limited wave growth considered, given in chronological order

1. US Army Corps of Engineers (1955)

2. Wilson (1955)

3. Groen en Dorrestein (1958)

4. Wilson (1965)

5. Mitsuyasu (1968, 1969; scaling with U*)

6. JONSWAP (Hasselmann et al., 1973)

7. Groen en Dorrestein (1976)

8. Shore Protection Manual (1977; also known as SMB-curves)

9. Shore Protection Manual (1984)

10. Donelan et al. (1985)

11. Dobson et al. (1985)

12. Kahma and Calkoen (1992; scaling with U10 and U*)

13. Donelan et al. (1992)

14. Dupuis et al. (1996)

15. Young and Verhagen (1996a, b, c)

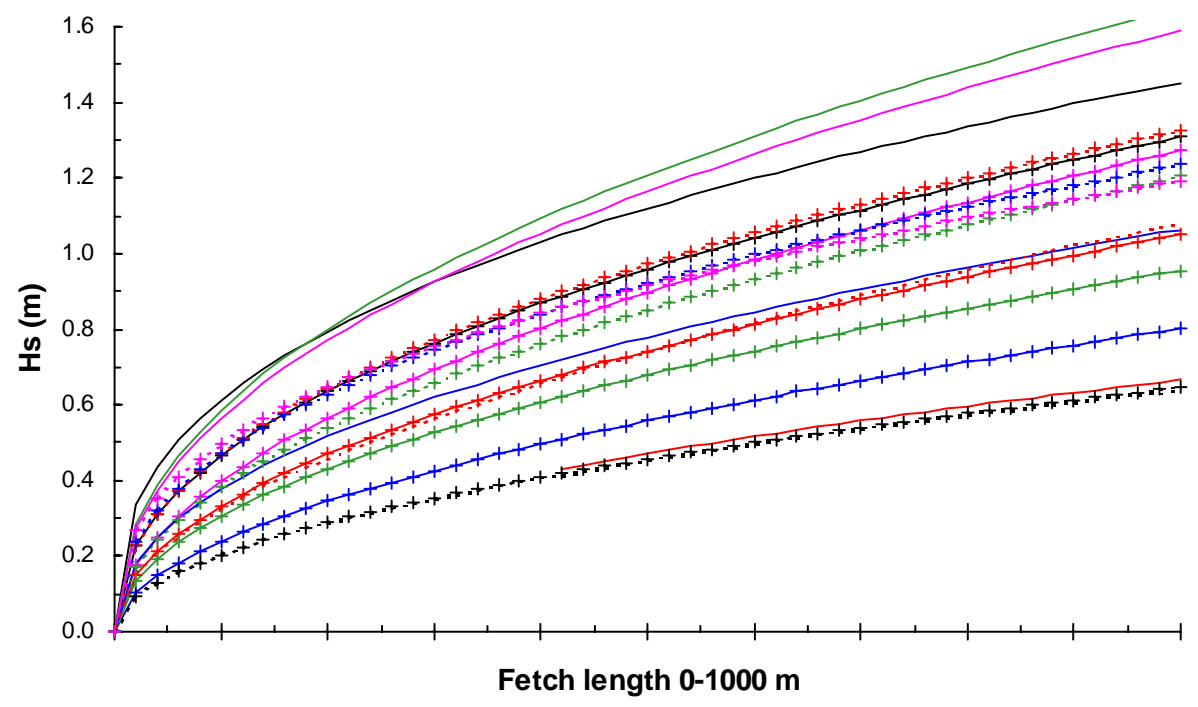

Fig. 6. Wave growth over $1000 \mathrm{~m}$ for a wind speed of $40 \mathrm{~m} / \mathrm{s}$, according to the references in Table 1, showing the considerable scatter

The following conclusions, amongst others, were drawn in Ris et al., 2000:

o From the wave growth curves considered, only those of US Army Corps of Engineers (1955), Wilson $(1955,1965)$ and Mitsuyasu $(1968,1969)$ are based on data that lie within the range of application.

o The Wilson $(1955,1965)$ formulations are considered to give the best estimate of 
wave growth at short fetches and high wind speeds. The main reasons for this are that his data come as close as possible to the area of application considered, and that, considering the total number of observations, an adequate fit to the data has been obtained.

Assuming that $U=U_{10}, H=H_{s}$ and $c=g T_{s} / 2 \pi$ in Wilson's formulations, the following formulations for wave growth in deep water were derived by Wilson (1955):

$$
\begin{aligned}
& \overbrace{\frac{H_{s} g}{U_{10}^{2}}=}^{10^{-1}<\frac{g X}{U_{10}^{2}}} \overbrace{0.26 \tanh \left(0.01\left(\frac{g X}{U_{10}^{2}}\right)^{0.5}\right)}^{2.6 \times 10^{-3}\left(\frac{g X}{U_{10}^{2}}\right)^{0.5}} \\
& \frac{T_{s} g}{U_{10}}=1.42 \pi \tanh \left(0.0436\left(\frac{g X}{U_{10}^{2}}\right)^{0.33}\right) \\
& 6.02 \times 10^{-2} 2 \pi\left(\frac{g X}{U_{10}^{2}}\right)^{0.33}
\end{aligned}
$$

where: $H_{s}=$ significant wave height; $g=$ acceleration of gravity $U_{10}=$ wind speed at $10 \mathrm{~m}$ height; $\mathrm{T}_{\mathrm{s}}=$ significant period and $\mathrm{X}=$ fetch length.

\section{Combination of Wave Transmission and Local Wave Growth}

As described in the previous section, local wave growth for short fetches and high wind speeds can be calculated by formula 2 . One of the problems with local wave growth in a complex area is that, due to wave transmission, energy is already present at high frequencies (the right part of Fig. 4). This has to be taken into account. Furthermore, some numerical models (e.g. SWAN) predict the local wind growth badly in the presence of the longer waves, see also Holthuijsen et al. (2000). This was avoided by decoupling the modeling of longer waves from the short waves in the harbour.

The combination of short wave energy, due to wave transmission and local wave growth, has been treated as follows:

o The transmitted wave height for the high frequencies has been calculated (Fig. 4)

o The fetch length was calculated for the relevant wind speed that would give the same wave height as the transmitted wave height

o This artificial fetch length was added to the actual fetch length between low-crested structure and flood defence structure

o Formula 2 was used with the total fetch length. This resulted in another wave height, $\mathrm{H}_{\mathrm{m} 0,2}$, with a short wave period, $\mathrm{T}_{\mathrm{p}, 2}$ at the flood defence structure.

\section{BI-MODAL SPECTRA AT THE STRUCTURE}

Wave transmission and local wave growth give energy at different frequencies, which results in a bi-modal spectrum, described by $\mathrm{H}_{\mathrm{m} 0,1} ; \mathrm{H}_{\mathrm{m} 0,2} ; \mathrm{T}_{\mathrm{p}, 1}$ and $\mathrm{T}_{\mathrm{p}, 2}$. Most design formulae, such as those for overtopping or stability, represent the wave spectrum using a single wave height and period. Therefore, an equivalent characteristic period must be calculated, based on the bi-modal spectrum. The concept by Mendez Lorenzo et al. (2000) was modified slightly so that it was also applicable for vertical seawalls. The formula for the total wave height, $\mathrm{H}_{\mathrm{m} 0}$, is given by: 


$$
H_{m 0}=\sqrt{H_{m 0,1}^{2}+H_{m 0,2}^{2}}
$$

and for the equivalent peak period by:

$$
T_{p e q}=\left(\frac{H_{m 0,1}}{H_{m 0}}\right)^{2} T_{p, 1}+\left(\frac{H_{m 0,2}}{H_{m 0}}\right)^{2} T_{p, 2}
$$

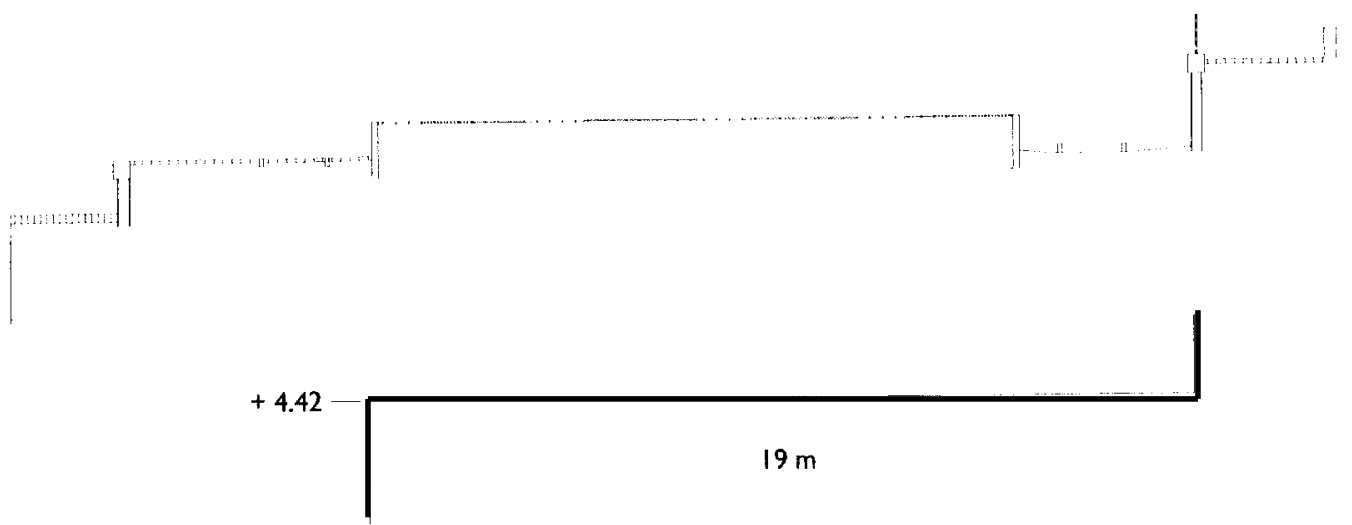

Fig. 7. Quays at various levels in front of a vertical wall which had to be increased.

The lowest figure is the schematisation for calculation
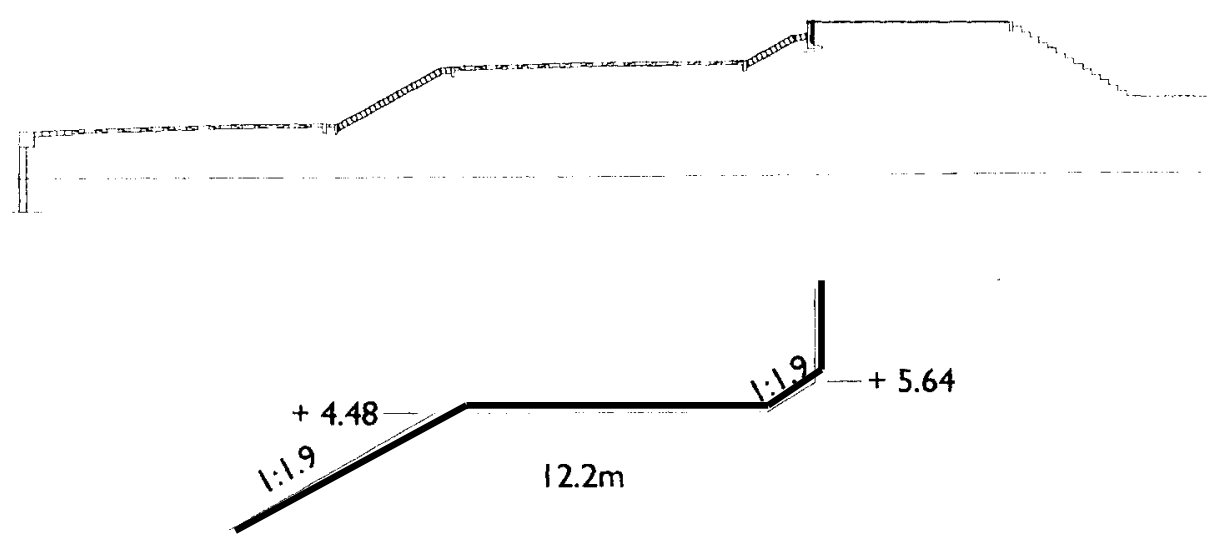

Fig. 8. Quays at various levels, two slopes and a vertical wall which had to be increased.

The lowest figure is the schematisation for calculation
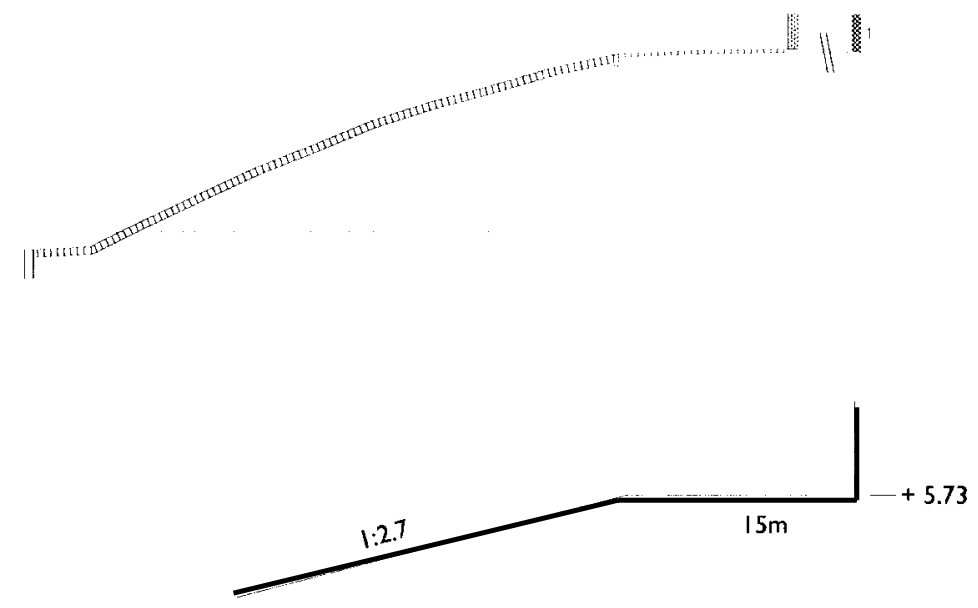

Fig. 9. A slope with a horizontal crest above swl and the location of a vertical wall, which had to be increased. The lowest figure is the schematisation for calculation

van der Meer, Langenberg, Klein Breteler, Hurdle and den Heijer 


\section{VARIOUS TYPES OF STRUCTURES}

Crest height design is often determined by the allowable overtopping. Many types of structures exist with each their own formula for wave overtopping. Various structure types as seawalls, dikes, vertical walls and combinations, were present at the location of the project. Examples of cross-sections considered, with a schematization for calculation of overtopping, is given in Figures 7-9. The water level considered was $+5.55 \mathrm{~m}$.

Model research was performed at Delft Hydraulics on combinations of slopes with (small) vertical walls and very shallow (flooded) quay areas with vertical walls. Figure 10 gives the tested cross-sections. The results of these tests, including prediction formulae are given by den Heijer, 1998. A further analysis for the project was described in den Heijer, 2001.
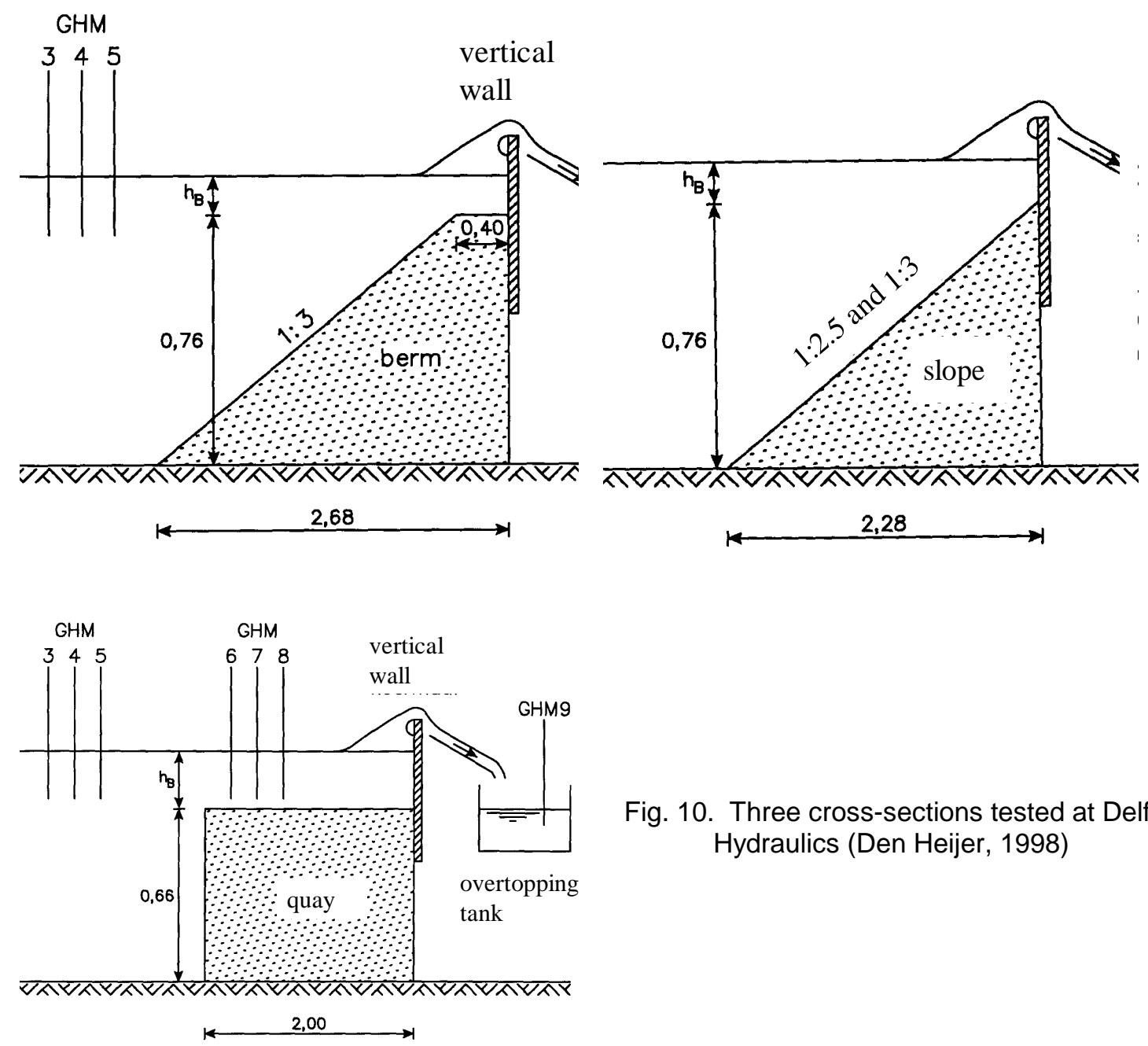

Fig. 10. Three cross-sections tested at Delft Hydraulics (Den Heijer, 1998)

\section{WAVE OVERTOPPING FORMULAE}

The following types of structures were distinguished and will be treated in the following:

o Vertical walls

o Dikes (slopes with a possible berm)

o Vertical wall on top of a slope (including a berm on top of the slope)

o Vertical wall on top of a (relatively short) quay. 
Overtopping formulae predict the mean discharge for a certain structure. It is also possible from the same formulae to calculate the required crest height of a structure, given a certain allowable overtopping discharge. Formulae in this paper are written as "overtopping" formulae (with q on the left side), but can be rewritten to required crest height formulae.

\section{Overtopping on Vertical Walls}

Various overtopping formulae for vertical structures were published in the past ten years, mainly based on European Research projects like MCS and PROVERBS. Comparison of the formulae showed considerable scatter. No clear explanation could be found. Based on five different formulae, including the overtopping data, a decision was made for the formula to be used in a new Dutch guideline on vertical flood defence structures. This formula can be considered as fairly conservative, due to the scatter described above, and is given by:

$$
q=0,13 \sqrt{g H_{s}^{3}} \exp \left(-3,0 \frac{R_{c}}{H_{s}} \frac{1}{\gamma_{\beta} \gamma_{n}}\right)
$$

with: $\mathrm{q}=$ mean overtopping discharge $\left(\mathrm{m}^{3} / \mathrm{s}\right.$ per $\mathrm{m}$ width)

$\mathrm{H}_{\mathrm{s}} \quad$ = significant wave height $\left(\mathrm{H}_{\mathrm{m} 0}\right.$ or $\mathrm{H}_{1 / 3}$ in $\left.\mathrm{m}\right)$

$\mathrm{R}_{\mathrm{c}} \quad=$ relative crest height with respect to swl (m)

$\gamma_{\beta}=$ reduction factor for angle of wave attack

$\gamma_{\mathrm{n}} \quad=$ reduction factor for a wave return wall or "nose"

The reduction factor for oblique wave attack can be described by:

$$
\begin{aligned}
& \gamma_{\beta}=1 \text { for } \beta \leq 20^{\circ} \\
& \gamma_{\beta}=\cos \left(\beta-20^{\circ}\right) \text { for } \beta>20^{\circ}, \text { with a minimum of } \gamma_{\beta}=0,7
\end{aligned}
$$

The reduction factor for a wave return wall or nose is given by:

$$
\begin{aligned}
& \gamma_{n}=1.0 \text { if } \mathrm{R}_{\mathrm{c}} / \mathrm{H}_{\mathrm{s}} \leq 0.5 \text { and } \gamma_{\mathrm{n}}=0.7 \text { if } \mathrm{R}_{\mathrm{c}} / \mathrm{H}_{\mathrm{s}}>1.0 \\
& \gamma_{\mathrm{n}}=1.3-0.6 \mathrm{R}_{\mathrm{c}} / \mathrm{H}_{\mathrm{s}} \text { for } 0.5<\mathrm{R}_{\mathrm{c}} / \mathrm{H}_{\mathrm{s}} \leq 1.0
\end{aligned}
$$

\section{Overtopping on Dikes}

Extensive research on wave overtopping on dikes has been performed in the Netherlands. One summary reference is Van der Meer et al., 1998. The formulae are given by:

$$
\frac{q}{\sqrt{g H_{s}^{3}}}=\frac{0.06}{\sqrt{\tan \alpha}} \gamma_{b} \xi_{o p} \exp \left(-4.7 \frac{R_{c}}{H_{s}} \frac{1}{\xi_{o p} \gamma_{b} \gamma_{f} \gamma_{\beta} \gamma_{v}}\right)
$$

with as maximum:

$$
\frac{q}{\sqrt{g H_{s}^{3}}}=0.2 \exp \left(-2.3 \frac{R_{c}}{H_{s}} \frac{1}{\gamma_{f} \gamma_{\beta}}\right)
$$

with:

$\tan \alpha=$ average slope of the structure

$\gamma_{\mathrm{b}}=$ reduction factor for $\mathrm{a}$ berm 


$$
\begin{array}{ll}
\xi_{\mathrm{op}} & =\text { breaker parameter }\left(\tan \alpha / \sqrt{g H_{s} /\left(2 \pi T_{p}^{2}\right)}\right) \\
\gamma_{\mathrm{f}} & =\text { reduction factor for roughness } \\
\gamma_{\mathrm{v}} & =\text { reduction factor for a vertical wall on top }
\end{array}
$$

For definitions of $\tan \alpha, \gamma_{\mathrm{b}}, \gamma_{\beta}$ and $\gamma_{\mathrm{f}}$, one is referred to Van der Meer et al., 1998.

\section{Overtopping on Vertical Wall on Top of a Slope}

In some situations it may occur that a vertical wall at the top of a slope has been designed to reduce wave overtopping. These walls are relatively small and not comparable with vertical structures like caissons or quay walls. Due to limited research the application of a reduction factor $\gamma_{v}$ is restricted by the following area:

o slopes from $1: 2.5$ to $1: 3.5$, possibly with a berm with dimensions $\mathrm{B} / \mathrm{H}_{\mathrm{s}}=2-3$ or $\mathrm{B} / \mathrm{L}_{\mathrm{op}}=0.05-0.08$

$\mathrm{o}$ the toe of the wall should lie between $1.2 \mathrm{H}_{\mathrm{s}}$ above and below the still water level

o the minimum height of the wall (with a high toe level) is about $0.5 \mathrm{H}_{\mathrm{s}}$ and the maximum height (with a low toe level) is about $3 \mathrm{H}_{\mathrm{s}}$.

The procedure to find an average slope has been defined in by Van der Meer et al., 1998. With a vertical wall that procedure will very soon lead to a large value of the breaker parameter $\xi_{\text {op }}$, which means that waves do not break in such situations. In fact the wall is situated at the top of a slope and waves will possibly break on the slope before they reach the wall. In order to keep the relationship between the type of breaking and the breaker parameter, the vertical wall has to be schematised as a 1:1 slope, starting at the toe of the wall. Then the procedure to establish an average slope can be applied.

The reduction factor for a vertical wall on top of a slope in equations 8 and 9 is $\gamma_{v}=0.65$. Wave overtopping will increase again if the wall is not completely vertical, but a little sloping. With a steep slope of 1:1 the reduction factor becomes $\gamma_{v}=1$. For a steeper slope, between 1:1 and vertical, one may interpolate linearly:

$$
\gamma_{\mathrm{v}}=1.35-0.0078 \alpha_{\text {slope }}
$$

with $\alpha_{\text {slope }}=$ the angle of the steep wall (between $45^{\circ}$ at $1: 1$ and $90^{\circ}$ for a vertical wall). A wave return wall or nose will further reduce overtopping according to equation 7 .

\section{Overtopping on a Vertical Wall on Top of a (relatively short) Quay}

The development of an overtopping formula for a wall on a quay has been described by den Heijer, 1998, and is based on only one quay width of $2 \mathrm{~m}$ in the physical model, see Figure 10. Due to limited research the application of the formulae, described further on, is restricted by the following area:

o the relative crest height: $1<\mathrm{R}_{\mathrm{c}} / \mathrm{H}_{\mathrm{s}}<3$

o the quay should be below swl

o the relative length of the quay: $0.25<\mathrm{L}_{\mathrm{B}} / \mathrm{L}_{\mathrm{op}}<0.5$

with $\mathrm{L}_{\mathrm{B}}=$ the width of the quay and $\mathrm{L}_{\mathrm{op}}=$ the wave length $\mathrm{gT}_{\mathrm{p}}{ }^{2} / 2 \pi$. The water depth above the quay is described by $h_{B}$. 
For a situation with a quay and a vertical wall (lowest situation in Figure 10), the average slope angle which determines the breaker parameter $\xi_{\text {op }}$, has been related to the width of the quay and the location with respect to swl:

$$
\tan \alpha=\frac{h_{B}}{3 H_{s}}+\left(1-\frac{h_{B}}{3 H_{s}}\right)\left(\frac{2 H_{s}}{L_{B}+2 H_{s}}\right)
$$

If the water depth above the quay is more than $3 \mathrm{H}_{\mathrm{s}}$, than the wall is considered as a structure on its own and formula 5 applies.

The formulae 8 and 9 for a dike are used, but with above procedure to determine the average slope angle, and with a reduction factor $\gamma_{\mathrm{q}}$ applied in the exponent of both formulae. The reduction factor for a quay is given by:

$$
\begin{array}{ll}
\gamma_{\mathrm{q}}=0.6+\frac{0.4}{1.5}\left(-\frac{h_{B}}{H_{s}}+3\right) \text { for } 1.5 & <\mathrm{h}_{\mathrm{B}} / \mathrm{H}_{\mathrm{s}}<3 \\
\gamma_{\mathrm{q}}=0.4+\frac{0.6}{1.5}\left(\frac{h_{B}}{H_{s}}\right) & \text { for } 0.5<\mathrm{h}_{\mathrm{B}} / \mathrm{H}_{\mathrm{s}}<1.5 \\
\gamma_{\mathrm{q}}=0.6 & \text { for } \mathrm{h}_{\mathrm{B}} / \mathrm{H}_{\mathrm{s}}<0.5
\end{array}
$$

Sometimes a geometry of a structure can not exactly be characterized as one of the structures described above. The best procedure is then to schematize the cross-section to two different structures, where formulae are available, and to interpolate between the predictions. For example a quay which is longer than half the wave length $\left(0.5 \mathrm{~L}_{\mathrm{op}}\right)$, can be schematized to a structure with a quay of $0.5 \mathrm{~L}_{\text {op }}$ and a structure with a quay width of more than one wave length. The latter is so long that it can be considered as a horizontal foreshore and the wave height becomes half the water depth at the vertical wall. Then overtopping over the vertical wall can be calculated (formula 5). Interpolation between the results of the two schematizations, using the quay width as determining parameter, will give a fair prediction of the overtopping or required crest height.

\section{CONCLUSIONS}

o Wave transmission over smooth and impermeable low-crested structures is not dependent on the crest width. This in contrast to rubble mound structures.

o Wave transmission causes a change in spectral shape with more energy at higher frequencies. A method to predict the spectral shape has been given. Together with possible local wave growth this gives a bi-modal spectrum behind the low-crested structure.

o Wave growth for short fetches and high wind speeds needs special treatment. Many wave growth formulae were not validated for this situation and predict consequently unreliable wave heights and periods in this situation. The formula of Wilson (1955) was considered as the most reliable one.

o A summary of overtopping formulae was given for various kind of structures. 


\section{REFERENCES}

d'Angremond K., J.W. van der Meer and R.J. de Jong, 1996. Wave transmission at low crested structures. Proc. $25^{\text {th }}$ ICCE, 1996, ASCE, 3305-3318.

Booij, N., L.H. Holthuijsen, and R.C. Ris, 1999: A Third-Generation Wave Model for Coastal Regions. 1, Model Description and Validation. J. Geophys. Res., Vol. 10, No. C, 7649-7666

Den Heijer, F., 1998. Golfoverslag en krachten op verticale waterkeringsconstructies (Wave overtopping and forces on vertical structures). Delft Hydraulics Report H2014, August 1998. In Dutch.

Den Heijer, F., 2001. Verbetering waterkering Harlingen. Hydraulische randvoorwaarden en kruinhoogten (Improvement of water defences at Harlingen. Hydraulic boundary conditions and required crest heights). Delft Hydraulics Report H3756, July 2001. In Dutch.

Holthuijsen, L.H., R.C.Ris, N. Booij and E. Cecchi. 2000. Swell and whitecapping, a numerical experiment. Proc. 27th ICCE, Sydney, Australia, ASCE, 346-368.

Melito, I and J.A. Melby, 2002. Wave runup, transmission, and reflection for structures armoured with core-loc. J. of Coastal Engineering 45 (2002) 33 - 52. Elsevier.

Mendez Lorenzo, A.B., J.W. van der Meer and P.J. Hawkes. 2000. Effects of bi-modal waves on overtopping: application of UK and Dutch prediction methods. Proc. 27th ICCE, Sydney, Australia, ASCE, 2114-2127.

Mitsuyasu, M., 1968. On the growth of the spectrum of wind- generated waves (I). Reports of Research Institute for Applied Mechanics, Kyushu University, Vol.16, N0. 55, 459482.

Mitsuyasu, M., 1969. On the growth of the spectrum of wind- generated waves (II),-- Note on the equilibrium spectrum and the overshoot phenomena-- Reports of Research Institute for Applied Mechanics, Kyushu University, Vol.17, N0. 59, 235-248.

Ris, R.C., D.P. Hurdle, G.Ph. van Vledder, L.H. Holthuijsen. 2001. Deep water wave growth at short fetches for high wind speeds. WL|Delft Hydraulics report H3817.

Seabrook S.R. and K.R. Hall, 1998. Wave transmission at submerged rubble mound breakwaters. Proc. $26^{\text {th }}$ ICCE,1998,ASCE ,2000-2013.

US Army Corps of Engineers, 1955. Waves and wind tides in shallow lakes and reservoirs. Lake Okeechobee, Florida. Summary Report on project CW-167, Office of the District Engineer, Jacksonville, June 1955.

Van der Meer J.W. and I.F.R. Daemen, 1994. Stability and wave transmission at low crested rubble-mound structures. J. of Waterway, Port Coastal and Ocean Engineering, 1994,1,1-19.

Van der Meer, J.W., P. Tönjes and J.P. de Waal, 1998. A code for dike height design and examination. International Conference on Coastlines, Structures and Breakwaters '98, 19-20 March 1998, Institution of Civil Engineers, London, UK.

Van der Meer, J.W., H.J. Regeling and J.P. de Waal. 2000. Wave transmission: spectral changes and its effects on run-up and overtopping. Proc. 27th ICCE, Sydney, Australia, ASCE, 2156-2168.

Wilson, B.W., 1955. Graphical approach to the forecasting of waves in moving fetches. Beach Erosion Board. US Corps of Engineers, Department of the Army. Technical Memo 73.

Wilson, B.W., 1965: Numerical prediction of ocean waves in the North Atlantic for December 1959. Deutsch. Hydrogr. Z., 18, No. 3, 114-130. 